\title{
Biological Pollution Control Technology Boost Ecological Civilization Construction
}

\author{
Shanshan Luo*, Xiaodan Wu, Yun Li \\ State Key Laboratory of Food Science \\ Nanchang University \\ Nanchang, China \\ *Luoss82@163.com
}

\author{
Yuhuan Liu*, Yiqin Wan, Yunpu Wang \\ Engineering Research Center of Biomass Conversion, \\ Nanchang University \\ Nanchang, China \\ *liuyuhuan@ncu.edu.cn
}

\begin{abstract}
China is the largest and fastest developing country in the world. Its rapid economic growth has led to rapidly increasing energy consumption and serious pollution. Jiangxi province is the most important livestock and poultry base. Along with the economic development and the improvement of people's living standards, Jiangxi is confronted with severe pollution problems because of the rapid development of the livestock and poultry industry which bringing serious challenges to the ecological environment. Cultivating microalgae by biogas slurry is an effective method of biological pollution control. Taking a demonstration project which can realize energy microalgae cultivation and livestock biogas slurry deep purification as example, the difficulties in practice of biogas slurry cultivating microalgae are analyzed and countermeasures to the problems are discussed in details.
\end{abstract}

Keywords- Ecological civilization; large-scale livestock farming enterprises; environmental pollution; the microalgae pollution control; circular economy

\section{INTRODUCTION}

China is the largest and fastest developing country in the world. Its rapid economic growth has led to rapidly increasing energy consumption and serious pollution. Facing with increasing resource constraints, severe environmental pollution and the deteriorating ecosystem, Chinese government and people must raise ecological awareness of the need to respect, accommodate and protect nature. The government must give high priority to make ecological progress and incorporate it into all aspects and the whole process of advancing economic, political, cultural, and social progress, and work hard to build a beautiful country, and achieve lasting and sustainable development of the Chinese nation [1]. Promoting ecological progress is a long-term task of vital importance to the people's well being and China's future.

\section{LIVESTOCK AND POULTRY INDUSTRY POLLUTION CALLS FOR BIOTECHNOLOGY}

In recent years, Jiangxi province, the most important and major livestock and poultry base has been developing very fast. According to statistics, the number of total slaughtered pigs in Jiangxi province in 2012 exceeded 30 million, poultry 410 million, cattle 1.401 million. The province's meat output reached 3.20 million tons, eggs 535 thousand tons, milk 127 thousand tons. The animal husbandry output value was 73.44 billion yuan, accounting for $33.3 \%$ of the total output value of the province's agriculture, forestry, animal husbandry and fishery. The proportion of large-scale pig farms was $19 \%$ higher than the national average.

However, the rapid development of the livestock and poultry industry has brought serious problems to the ecological environment. Livestock and poultry breeding pollution have far exceeded the industrial and domestic pollution. COD emission in the excrement of livestock and poultry industry is five times that of the province's industrial and domestic wastewater [2]. The ammonia nitrogen emission is seven times. Therefore, livestock and poultry manure pollution has become the severest problem influencing the province's ecological environment, among which the pollution in the pig industry is the major problem. Thus, solving the pollution problems of the livestock and poultry industry is becoming an urgent issue [3].

Large-scale aquaculture is the main emission source of greenhouse gases of $\mathrm{CO}_{2}, \mathrm{~N}_{2} \mathrm{O}$ and $\mathrm{CH}_{4}$. Authoritative statistics show that meat food production is the major release of greenhouse gases, accounting for $18 \%$ of global greenhouse gas emissions, which means it will emit $36.4 \mathrm{~kg}$ of carbon dioxide when producing $1 \mathrm{~kg}$ meat [4].

Manure management systems including storage and processing are often inadequate. Most companies do not take appropriate measures to prevent pollution. In recent years, although most of the livestock and poultry enterprises have built biogas tank with the government's support, biogas slurry has not been effectively processed to meet the national emission standards due to the high cost to process the manure. In current station, four major problems have to be considered carefully. First, the consumptive capacity of biogas slurry by the paddy fields is limited. Biogas slurry has been mixed with irrigation water, causing excess nutrients of rice. Second, the inadequate reservoir pools for livestock biogas slurry inevitably result in biogas slurry's overflowing onto the ground, seeping into the groundwater, and endangering the soil and water. Third, poor quality biogas and poorly treated biogas cause atmospheric pollution. Finally, the poor farm environment in turn raises the risk of pig disease which leads to the abuse of antibiotics. And meat food safety declines [5].

In China, most farm, enterprises store biogas in its natural state. It results in environmental hazards. In recent years, a small part of enterprises has adopted measures of 
municipal wastewater treatment and gas purification engineering, but the high maintenance costs limit the promotion.

Ecological civilization arouses great concern to the livestock and poultry industry pollution control [6]. Cost-efficient biogas slurry purification by microalgae and production of microalgae feed and bioenergy has become the inevitable choice to develop the recycling industry, low-carbon economy and to enhance the quality of meat, poultry, eggs and milk.

\section{Microalgae Cultivation by Biogas Slurry: AN EFFECTIVE CONTROL OF BIOLOGICAL POLLUTION}

On the basis of large agricultural circular economy theory, it is possible to achieve sustainable utilization of waste [7] by encouraging companies to utilize waste as biogas energy, organic fertilizer to gain high-quality algae feed, organic vegetables, organic herbs and so on. Waste utilization cycle is formed through the method of making use of waste in previous industrial chain as the raw materials in next chain [8].

The use of fossil fuels is now widely accepted as unsustainable due to depleting resources and the accumulation of greenhouse gases in the environment that have already exceeded the "dangerously high" threshold of $450 \mathrm{ppm} \mathrm{CO}_{2}$. To achieve environmental and economic sustainability, fuel production processes are required that are not only renewable, but also capable of sequestering atmospheric $\mathrm{CO}_{2}$. Currently, nearly all renewable energy sources (e.g. hydroelectric, solar, wind, tidal, geothermal) target the electricity market, while fuels make up a much larger share of the global energy demand (similar to $66 \%$ ). Biofuels are therefore rapidly being developed.[9]

Algal biofuel production offers great potential as a sustainable source of bioenergy without competing for arable land with food crops. However, many challenges must be overcome to enable this to be done commercially at the scale required to produce biofuels.[10] Microalgae, with the merits of environmental adaptability, high photosynthetic efficiency and high lipid content, have become one of the most promising raw materials for bio-fuels production, especially for the biodiesel production. 2 While current approaches have limitations for efficient and cost-effective microalgal biofuel production, new processes, which are financially economic, environmentally sustainable, and ecologically stable, are needed.[11]

Biofuels derived from microalgae are the most possible alternatives to fossil fuels due to the algae's intrinsic characteristics of fast growth rate, high lipid content, not competing with food and arable land, and capability of $\mathrm{CO}_{2}$ sequestration. However, growing algae requires large amounts of water and nutrients. It also takes a lot of energy to harvest and convert. One promising way to make algal biofuel production more cost-effective is to couple with wastewater treatment [12].

In May 2012, Professor Roger Ruan, an internationally renowned expert in the field of bio-energy, led his team to create a system which realized livestock wastewater treatment and microalgae bio-energy development in a large-scale pig farm. It consists of four parts. They are the primary biogas slurry processing system by bacteria and algae symbiotic float in oxidation pond, the economic microalgae cultivation system, the value-added processing system of microalgae biomass, and biogas purification subsequent ecological utilization system [13].

After more than a year's hard work, the relevant research institution and the basic construction in Pingxiang Eucommia pig breeding base were completed. Currently, all the biogas slurry realizes firstly treatment and $20 \%$ of the slurry obtain a secondary treatment. After purifying, the parameters of every contamination are much lower than the national standard of water livestock and poultry.

The current facilities investments for pollution control and biogas purification is $60 \%$ cheaper per ton biogas slurry than the traditional municipal activated sludge treatment facilities[14]. At the same time, pollution control using microalgae brings further profits, such as biodiesel and algae-based immunotherapy feed. After the secondary purification by microalgae, wastewater can also be used to irrigate herbs, organic vegetables, lotus root and rice. In all, pollution control using microalgae extends the industrial chain, and is beneficial to the corporations.

\section{RATIONAL THINKING ON OF BIOTECHNOLOGY GOVERNANCE LIVESTOCK INDUSTRY BIOGAS}

The State Council recently enacted a plan to accelerate the development of bio-industry, bio-environmental protection and bio-energy industry. Biotechnology is not only an effective way to achieve the sustainable development of the livestock and poultry industry, but also is important to build bio-environmental protection and bio-energy industries.

The Pingxiang biogas slurry cultivating algae demonstration project has obtain remarkable success in the past year. It is necessary and feasible to establish a group of energy microalgae pollution control systems in the entire province. The biogas slurry cultivating economy (energy) microalgae technology will definitely be effective to the province livestock and poultry pollution control and bio-environmental protection. The development of bio-energy industry will reach higher level.

Practices have shown that there is a contradiction between the livestock and poultry breeding efficiency and pollution control. To solve this contradiction, we need to enhance awareness and properly deal with the following five relationships [15].

Firstly, the interest of companies should be coordinated with their social responsibility. The companies should consider fully the cost of breaking the law before they take business operations. The law must be carried out strictly in order to control pollution effectively.

Secondly, funds and technology support is required from different government department, other technology agencies and so on.

So far, we have achieved some success in biogas slurry breeding energy microalgae project, but still face problems, such as lack of funds, technology and etc. In terms of money, the corporations mainly provided support in infrastructure 
and human resource, but they do not invest money due to the worry of capital loss.

To solve this problem, relevant government agencies, institutions, companies need to provide policy and financial support such as electricity, tax, equipment, utilization of the land and etc. In the aspect of technology, new technology should be applied. The equipment should be improved further. Universities and research institutes should give their best technical support to the enterprises and cooperate with them.

Thirdly, the core industry of the corporate and its affiliated industry develop coordinately. Taking the Pig breeding base in Jiangxi Eucommia Development Co., Ltd. Pingxiang as an example, breeding high-grade Green Mitt pigs with microalgae Eucommia is the core industry. All pig manure is used to produce biogas. And biogas power generation can solve the enterprise demand for electricity. The biogas residue is high quality organic fertilizer for organic fruits, vegetables and microalgae. The harvested oil-bearing microalgae are not only the immunotherapy feed to pigs, but also the raw materials to produce biodiesel. In addition, after microalgae purification water can be used as supplemental water for downstream rice fields, fish ponds and ecological aquaculture. The cost of pollution control is offset by the benefits from affiliated industry.

Fifthly, it is necessary to control the animal protein intake and improve the quality of meat, poultry eggs and milk which is critically important for the people's health. According to statistics from Ministry of Agriculture, China's total meat consumption is 68 million tons, $52 \mathrm{~kg}$ per capita, far higher than the world average level. The meat consumption level of the urban population is more than 1.5 times that of the rural population. Especially around the large cities, the livestock and poultry breeding enterprise is dramatically intensive, resulting in deteriorating environment. High-density breeding of livestock worsens living conditions of livestock and poultry and degrades their immunity, which causing antibiotics and hormone abuse. The dead pig incident, occurred in Huangpu River in March 2013, is a typical and thought-provoking event.

Over the past decade, a large number of researches show that long-term high-protein diet is a negative impact on human health [11]. As a rough estimate, land producing one kilogram of animal protein can produce more than ten kilograms of plant protein. In view of this, we believe that large-scale livestock breeding has brought serious environmental problems in the context of today's population explosion. Excessive consumption of animal foods leads to hypertension, heart disease, stroke etc. in the urban population.

Controlling animal protein intake and improving quality should be harmonious unity in current food consumption levels, which will not only enhance the overall health situation of the urban population, but also improve the development of circular economy. Farming enterprises should be encouraged scientifically using traditional Chinese herbs or the microalgae as resources to enhance the quality of livestock and poultry products. The use of microalgae and Eucommia can be great aquaculture antibiotics extents reduce the use of heavy metals, while significantly reducing difficulty of the subsequent biogas biological treatment.

\section{ACKNOWLEDGMENTS}

This work was financially supported by the National High-tech R\&D Program of China (2012AA101800, 2012AA021704, and 2012AA021205). Natural Science Foundation of China (21266022) Science Foundation of Jiangxi Provincial Department of Education (KJLD 12011).

\section{REFERENCES}

[1]. Jiang, X.Y., S.G. Sommer, and K.V. "Christensen, A review of the biogas industry in China”. Energy Policy, 2011. 39(10): p. 6073-6081.

[2]. Ning, Z. and F. Chun, "Research on non-point source pollution resulted form livestock breeding in Jiangxi province", in Progress in Environmental Science and Engineering, H. Li, Q.J. Xu, and D. Zhang, Editors. 2012, Trans Tech Publications Ltd: Stafa-Zurich. p. 2344-2348

[3]. Xu, J., L. Wu, and J. Wei, "Reflections on circular economy of Jiangxi pig cultivation". Acta Agriculturae Jiangxi, 2008. 20(8): p. 170-172.

[4]. Liu, Y.B. and X.L. Jiang, "Modeling the Response of Environmental Pollutants to the Urbanization in Jiangxi Province, China". Proceedings of 2008 Conference on Regional Economy and Sustainable Development, ed. J. Hung, Z. Ruimei, and W. Zhang. 2008, Allawah Nsw: M D Forum. 1076-1080.

[5]. Jia, R., et al., "Developing the Breeding \& Planting Circular Economy System Engineering, Constructing Harmonious Society". 15th Annual Meeting ProceedingsChinese Institute of systems Engineering, Jiangxi Nanchang, 2008(10): p. 465-475.

[6]. Xu, S.P., J.D. Yin, and Z.F. Zeng, "Main Problems and the Countermeasures in the Transition of Resource-exhausted Cities in China: The Case of Pingxiang City, Jiangxi Province, China". Proceedings of the 2009 International Conference on Public Economics and Management Icpem 2009, Vol 7: Cluster Analysis, ed. R. Chen and S. Zhou. 2009, Liverpool: World Acad Union-World Acad Press. 162-166.

[7]. Jie, W., The "Economic Theory of Grand-agriculture Cycle and the Development of Western Agriculture". Journal of Guizhou University for Ethnic Minorities 2009 (4): p. 118-121.

[8]. Wang, C.X., "A SD perspective on pig-raising waste integrated utilization". Proceedings of the Fourth International Conference on Management Science and Engineering Management, ed. J.P. Xu, H. Rau, and Y. Jiang. 2010, Liverpool: World Acad Union-World Acad Press. 368-371.

[9]. Schenk, P. M.; Thomas-Hall, S. R.; Stephens, E.; Marx, U. C.; Mussgnug, J. H.; Posten, C.; Kruse, O.; Hankamer, B., Second Generation Biofuels: High-Efficiency Microalgae for Biodiesel Production. Bioenergy Research 2008, 1 (1), 20-43.

[10]. Zhou, W.G., et al., "A hetero-photoautotrophic two-stage cultivation process to improve wastewater nutrient removal and enhance algal lipid accumulation". Bioresource Technology, 2012. 110: p. 448-455.

[11]. Zhou, W.G., et al., "Novel Fungal Pelletization-Assisted Technology for Algae Harvesting and Wastewater Treatment". Applied Biochemistry and Biotechnology, 2012. 167(2): p. 214-228.

[12]. Chang, X., R. Rongsheng, and L. Yuhuan, "Impacts of high protein diet on human health: a review". Science and Technology of Food Industry, 2012. 33(21): p. 399-402.

[13]. Kazamia, E.; Aldridge, D. C.; Smith, A. G., Synthetic ecology - A way forward for sustainable algal biofuel production? J. Biotechnol. 2012, 162 (1), 163-169. 
[14]. Zhang, F.; Cheng, L. H.; Xu, X. H.; Zhang, L.; Chen, H. L., Technologies of Microalgal Harvesting and Lipid Extraction. Prog. Chem. 2012, 24 (10), 2062-2072.
[15]. Zhang, J. G.; Hu, B., A novel method to harvest microalgae via co-culture of filamentous fungi to form cell pellets. Bioresource Technology 2012, 114, 529-535. 